\title{
An Architecture to Combine Activity Traces and Reporting Traces to Support Self-Regulation Processes
}

\author{
Min $\mathrm{Ji}^{1,2}$, Christine Michel ${ }^{1,2}$, Elise Lavoué ${ }^{1,3}$, Sébastien George ${ }^{1,2}$ \\ ${ }^{1}$ Université de Lyon, CNRS \\ ${ }^{2}$ INSA-Lyon, LIRIS, UMR5205, F-69621, France \\ ${ }^{3}$ Université Jean Moulin Lyon 3, MAGELLAN, LIRIS, UMR5205, France \\ \{min.ji; christine.michel; elise.lavoue; sebastien.george\}@liris.cnrs.fr
}

\begin{abstract}
In this paper, we propose an architecture of ProjectBased Learning Management System (PBLMS). These systems offer learners indicators to support self-regulation in PBL. Indeed, when students are engaged in learning processes with LMS, they are supposed to be autonomous to find information or to organize their activities. Indeed, most of time, few tools are proposed to help them. Our research focuses on the tools which support meta-cognition process to teach learners how to regulate their learning activities during projects. In this paper, we propose a PBLMS architecture that combines together activity traces (which are recorded automatically by the system) and reporting traces (which are reported by learners themselves). This architecture allows learners to build indicators. They can specify the data to take into account and the visualization modes. We present the details of the reporting tool, used to collect reporting traces, which can enhance learners' reflective processes on their own way to learn.
\end{abstract}

Keywords-project-based learning; information architecture; self-regulation; activity traces; reporting; collaborative learning.

\section{INTRODUCTION}

The World Wide Web provides opportunities for creating virtual classrooms for learners and instructors [1]. Many software environments take advantage of the Internet and support open and distance education [2]. More and more educational institutions use LMS (Learning Management System) for their courses. Different studies about the use of LMS have pointed out that students may feel isolated due to the limited contact with the teachers and other students. They often find difficult to manage the resources without appropriate support. They may get disorientated in the course hyperspace and lose their motivation [1]. A solution to this problem is to give the possibility to learners and tutors to manage their learning activities. Educational research shows that monitoring the students' learning is an essential component of high-quality education, and is "one of the major factors differentiating effective schools and teachers from ineffective ones" [3]. For learners, the self-regulation of their activities can improve their ability to "learn how to learn", which is one of the learning objective in projectbased learning for example [4].

There are several methods to help users to manage their learning activities in LMS. We are interested in the methods that are based on activity traces. We define activity traces as the users' actions recorded directly by the LMS during the learning activities. There are other types of traces, such as the description of the carrying out of the activities and the activities results outside of the LMS, for instance homework or face-to-face discussions between learners and tutors. These traces are reported by the learners themselves, explaining how their (or their peers') activities are carried out. We call them reporting traces.

In the LMS, activity traces are usually used by tutors to monitor and evaluate learners or by learners in collaborative activities and self-confrontation. The reporting traces are used by tutors to give learners advices, but they are rarely used by learners themselves. Few information systems use both activity traces and reporting traces. Based on this observation, our research aims to supply a LMS that uses these two kinds of traces together to produce indicators. These indicators could be used by tutors to analyze learners' learning qualities and by learners to apply metacognitive strategies and self-regulation processes. These works are conducted in the context of Project-Based Learning (PBL) situations and previous works have shown the utility and usability of indicators to support self-regulation processes [5].

In this paper, at first, we study the tools that use traces to support metacognitive regulation. Then, we propose the architecture of an application based on Moodle, which uses both activity traces and reporting traces. This application is a PBLMS (Project-Based Learning Management Systems) [6]. Then, we describe the reporting module specifically, which is based on semi-structured sentences to construct the reporting traces. We finally conclude and describe further works.

\section{LEARNING MANAGEMENT SYSTEM SUPPORTING METACOGNITIVE REGULATION}

\section{A. Metacognitive Regulation}

Project-based learning is a pedagogical method often used for complex learning (i.e. which aims to make students acquire various linked skills or develop their behaviors) [4]. Collaborative learning through project-based activities promotes abstraction from experience, explanation of results, and understanding of conditions of projects in real world situations; it also provides the experiences of working in project groups [7]. During long term projects, learners are involved in a non-structured learning process: they have to define the tasks and the actions needed to achieve the 
learning goals, organize the works in the groups, adapt frequently the plans according to the project processes, etc. In order to do that, learners have to develop individual and collective self-regulation abilities. Zimmerman defined the self-regulation as: "self-generated thoughts, feelings and actions that are planned and cyclically adapted to the attainment of personal goals" [8]. The use of metacognitive tools is recommended to help them to do that.

Many different studies have pointed out that the learning activity traces are difficult to use by learners or tutors, even if they have participated in the activities. Indeed, Gagnière [9] has identified the limits of the self-use of activity traces comparing to the directed use of activity traces. She pointed out the fact that the potential of tools to use traces to support the metacognitive regulation depend on the way they propose execution functions (e.g. monitoring and control functions propose to user to help him to analyze the results of his actions and make decisions). In order to make metacognitive process effective, control and regulation must be performed by the learners rather than by the system.

The regulations proposed in LMS are elementary, but in most of cases are in fact non-existent. The general functions used by learners and tutors can be classified into seven major categories and fifteen sub categories [10]. Most designers focus on the creation, organization and assignation of different activities rather than the reflection and regulation processes. So we are interested in using traces to support regulation process in distance learning environments.

\section{B. Activity Traces in Learning Environments}

Different tools, such as ESSAIM [11] and FORMID [12], have been developed to help tutors to monitor learners' synchronous individual activities by using activity traces. These tools have been designed mainly for tutors. No function has been designed for learners to let them to manage their own learning activities during long periods. Croisiere [13] and Reflet [14] have been developed to monitor asynchronous learning activities and help learners to go to autonomy by regulating their learning activities. Croisière allows learners to choose the learning activities according to their own learning strategies. Reflet presents the progresses of a learner or a class and supply the feedback about it. Learners determine themselves the activities done in the course and tutors accept or not their plans according to the amounts of tasks they have finished.

TACSI [15] presents learners' activity traces collected in the case of collective projects (such as their contributions in the collective activities or discussions, their social behaviors). CourseVis [1] use activity traces produce by WebCT in order to compute graphical indicators about learning behaviors, social characteristics and cognitive evolutions of distance students. TrAVis [16] enables users to directly access to tracking data repository, by the way of a Graphical User Interface, in order to compute indicators and choose the visualization modes. It is a reflective tool giving students information about the way they carry out discussions or other collaborative activities. TrAVis is an independent tool and can be embedded in different LMS.
We noticed that most of the tools studied in this part are dedicated to teachers and tutors. Moreover, they are exclusively centered on monitoring students' activities but not on assisting students or tutors in reflecting on these activities [4]. A reflexive system supposed to help students to be autonomous and should give them guides about the realization of their activities with LMS and supply critical feedbacks about their learning. The tools presented in this part don't support metacognitive processes. Moreover they only collect activity traces in order to produce indicators automatically. Learners have no possibility to complete the traces by other information (such as thoughts, emotions, activities done outside of the LMS, etc.).

\section{Reporting Traces in Learning Environments}

Blogging has been increasingly recognized as a popular web technology for education, especially in distance learning settings. Blogs are designed to allow the simple and fast creation of web content by using publication functions of collaborative writing tools such as posts, comments, and instant hyperlinks to information sources [17], for example personal newspaper. Blogging has been recommended as a suitable tool for learning because knowledge build is considered to be better, quite like the ability to solve problems, to self-reflection or to communicate emotions [18].

Pco-Vision [5] is a dashboard applied in PBL by using the structured self-reporting. It provides learners with a global view on objectives-actions-results in order to support self-regulation and to develop complex abilities (e.g. evolution ability). The traces are self-declared and are presented in the dashboard into an individual view and a collective view. It has been confirmed that dashboards can support learners' self-judgment process, especially when dashboards present the information about how the activities are carried out.

Nevertheless, the reporting process of Pco-Vision, organized as self-declaration only about the current week, is considered by learners to be too much bindings [5]. Furthermore, no assistance is proposed to provide information about metacognitive processes. The designers of Pco-Vision pointed out [5] the need of contextualized data declaration interfaces and a lack of combining of reporting and activity traces. Conversely, learners find it is easy to write blogs but have difficulties to focus on subjects related to learning activities. Moreover, there is no guide defining the way a blog have to be organized to be effective to support reflection and metacognition processes. Therefore, it is difficult both for learners to write them and for tutor to give advices. Finally, blogs are non-structured texts and are hard to be analyzed automatically. Natural Language Processes (NLP) methods can be used to analyze the content of reports and help learners to discover specific information or relations between them. But language analyses cannot be completely automatized and so produced data cannot be continuously grasped with activity traces to produce indicators usable during a learning session or project. 


\section{Combination of Activity Traces and Reporting Traces in Learning Environments}

The system gStudy [19] is a collaborative learning platform proposing different methods of communication and collaborative writing to support distance learning: notes writing (notes), resume about courses' concepts (Strategy Library), concept maps (Concept map), discussion tool ( $g$ Chat) and personal ideas expression (Labels) about the coconstructed concepts and resources. The self-regulation and co-regulation are realized by the presentation of all these information directly or after being processed. The traces collected in gStudy are the log files and the messages in the gChat. The logs are structured according to an event model defined by 56 items: creation, deleting, updating of notes or concepts, creation of links between concepts or between notes (such as definition, relation of cause and effect, level of importance, agreement notification, etc.). The system supplies complementary information and interaction to help traces' analysis. In gChat, the key information about activities is pointed out. Roles taken by learners in the conversations are analyzed and are presented to them. Assistance messages (question or declaration) are provided to help learners to analyze and self-regulate their activities. The LogAnalyser tool produces indicators, such as the frequencies of events, the transition between events (in the forms of numbers and graphs) and the organization of events in a time-line. GStudy is the closest system to our research purpose. But its personalization level is too weak. Indeed, like all the systems introduced in section II.B, personalization is just possible for the visualization of indicators and not for the processes of data selection or data treatment. Therefore, learners cannot structure their own traces in order to build personalized indicators and so their level of involvement is limited.

The system TBS-IM [20] uses the concept of modeled trace (M-Trace) to enable user to create indicators from activity traces produced by Moodle. M-trace's structure let TBS-IM supply various transformation functions to build indicators: extraction of detailed information about activities, combination of them and choice of visualization modes. Other learners, from Moodle or from others learning contexts, can reuse the transformation processes to compute other indicators. TBS-IM architecture is relevant to the PBLMS construction but can be improved in order to process the reporting traces. In the next section, we present a PBLMS architecture designed to collect both the activity and reporting traces. It includes a reporting tool based on semistructured sentences to collect the reporting traces.

\section{A PROJECT-BASED LEARNING MANAGEMENT SYSTEM COMBINING ACTIVITY TRACES AND REPORTING TRACES}

In a PBL context, we think that external data (out of the computer learning environment) are as important as internal data collected by the learning environment. It is necessary to consider these two types of data for analyzing the activities in a global way. The aim of our research is to obtain highlevel analysis in order to help learners to improve their selfregulation and metacognitive skills. The difficulty is the combination of these different types of data. We found few systems that collect these two types of traces, but they process them separately. In this section, we propose a PBLMS based on Moodle, which can combine these two types of traces. In order to collect reporting traces, we developed a reporting tool, which can help learners to record information during the learning activities and assist them in reflecting on their behaviors.

\section{A. General Architecture of Project Based Learning Management System}

In order to give a global view of our proposal, we present a schema to explain the functioning of the PBLMS (Fig.1).

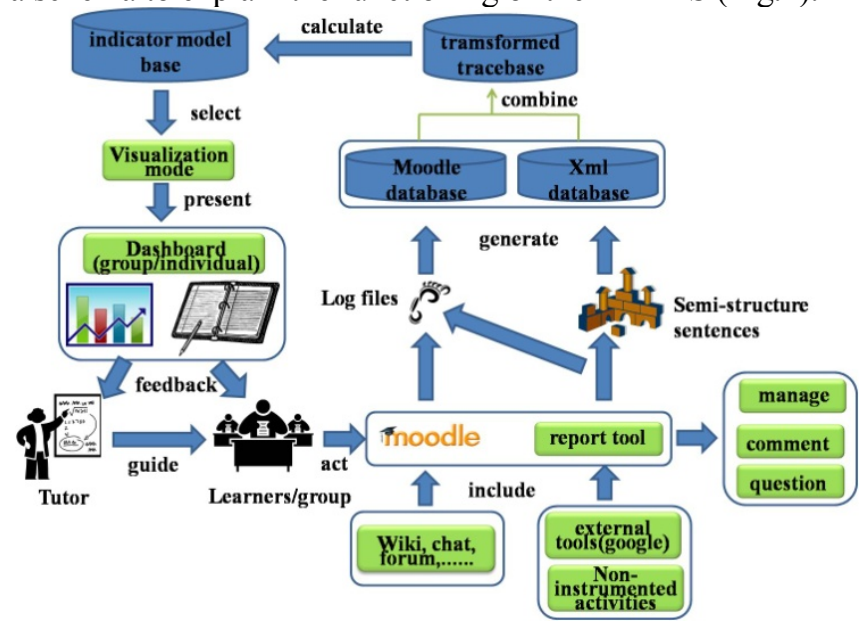

Figure 1. The global architecture of PBLMS.

After a tutor allocates a project to a group of learners, they use the Moodle tools (wiki, forum, chat...) to carry out the project and the reporting tool to write some information. The reporting tool assists learners in writing reports by supplying semi-structured sentences. The semi-structured sentences are more flexible than structured sentences but keep the possibility to collect organized and computable data. We propose a set of categories of semi-structured sentences to cover all the aspects of project-based learning activities. Learners can report information about non-instrumented activities or about the use of external tools independent from Moodle (Google, Skype....). The reports also could be shared with the other learners to support experience sharing. The semi-structured sentences of the reporting tool (reporting traces) and the traces of use of Moodle (activity traces) are recorded in a XML database (BaseX) and in a relational database (MySQL) respectively. These two kinds of traces are integrated according to a common time basis and then are stored into a transformed traces base. The transformed traces are used to produce indicators that are stored in a dedicated database. For the novices, they can construct their own dashboards by choosing and parameterizing the visualization modes of predefined indicators. And for the experienced learners, they can create new indicators. At last, the presentation of indicators will provide a feedback to the learners and tutors.

The reporting tool can collect the information related to the activity processes, the learners' emotions, the learning 
strategies and the learners' objectives. It can help to construct advanced indicators that represent learners' activities. For example, the indicators can support the analysis of behavior by comparing the learners' impressions about their activities (subjective) with the realization mode (objectively recorded by the way of traces). The indicators can support self-regulation and help to construct metacognitive skills by comparing the realized activities with the learning objectives or other learners' performances.

\section{B. Indicators of the Project Based Learning Management System}

In order to help learners to use indicators, it is necessary to present them in an organized way. We have classified the indicators into four categories: activity, cognitive, affective and social indicators. Activity indicators present the information about the activities' contents and the learners' behaviors, for example the working time, the density of the activities on a period, learners' feelings about activities (difficult or easy, interesting or boring) and the less/most active learners. Cognitive indicators present the information about the learners' knowledge level and the project results. It is related to the project goals. These indicators represent, for example the progress of the knowledge level, the most difficult (easiest) knowledge and the number of solutions proposed by each learner. Affective indicators represent the emotional state of the group members during the project. This type of indicators includes, for example learners' mood, motivation, and emotion trend during a period (individual and group). Social indicators are about the workspace and the interactions between actors. This information reflects the collaboration, coordination, social organization and conflicting or harmonious relations in the group.

In order to calculate these four kinds of indicators, relative observed elements (named obsels) should be collected. These elements compose the primary trace of the users' activities. We have classified the indicators according to the three categories of activities: (1) the internal activities, which occur in the Moodle environment (chat, wiki, forum...); (2) the external activities, which occur out of Moodle but still in the computer environment; (3) the noninstrumented activities, such as writing on a paper, visiting a factory, face-to-face activities including discussions and lectures, etc.. The reporting activity allows learners to record information about external and non-instrumented activities.

\section{Data Structure of the Reporting Tool}

There are 2 main classes in the database model of the reporting tool: the report class and the semi-structured sentences pool class. The report class contains the content and the basic information of the reports. The advice, questions and comments classes include the content of the advices, questions and comments related to a report. The semi-structured sentences pool class describes the sentence structures. The category, widgetType and widgetValue classes supply the data related to a sentence structure. The report structures class maintains the relationship between the report class and the semi structured sentence pool class. The report structures consist of several semi-structured sentences.
Thanks to the customized structures class, different report structures are given to different students. Therefore, students can have personalized report structures according to their own learning processes. We chose BaseX (http://basex.org/) as the database management system. It is a pure XML database that supports the W3C XPath/XQuery. Considering that the reporting traces are semantic and that the structures of reports are different, we chose to store reporting traces in the form of XML files.

\section{Functions of the Reporting Tool}

The development of the reporting tool is based on a Model-View-Controller architecture (MVC) (Fig. 2).

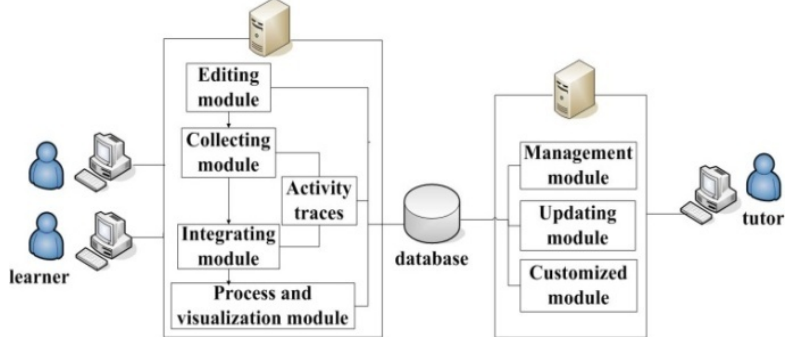

Figure 2. The architecture of the reporting tool.

The functions of the reporting tool can be divided into two parts: the learners' side and the tutors' side. In the tutors' side (Fig. 3), the management module allows tutors to read the learners' reports, add advices and questions and write comments on the reports. The updating module supplies the functions of editing (creating, updating, deleting) the semistructure sentences, building the report structures and maintaining the questions and advices pools, which facilitate the management work. The customized module allows tutors to propose different report structures to different learners according to their learning processes.

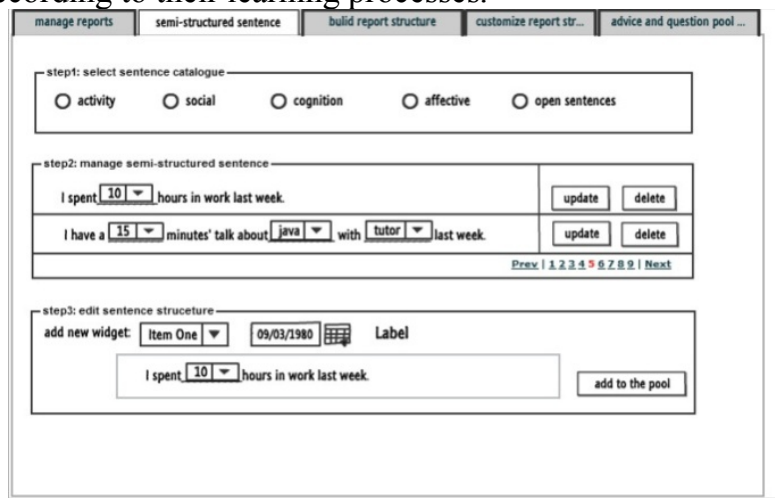

Figure 3. The tutors' interface: creation of semi-structured sentences.

With their interface (Fig. 4), learners can create a new report or update an old report in editing module. The interface lists their report structures consisting of several semi-structured sentences, which are assigned by the tutor. Learners can also manage their own reports and read others' reports with a public status. The system will collect the reporting traces (collecting module) and combine them with the activity traces (integrating module). At last, learners can do treatment on all the traces to create new indicators or new 
visualization modes (process and visualization module). By applying this reporting tool, learners can self-reflect on how they carried out the learning activities and learn how to organize their ideas and write effective reports.

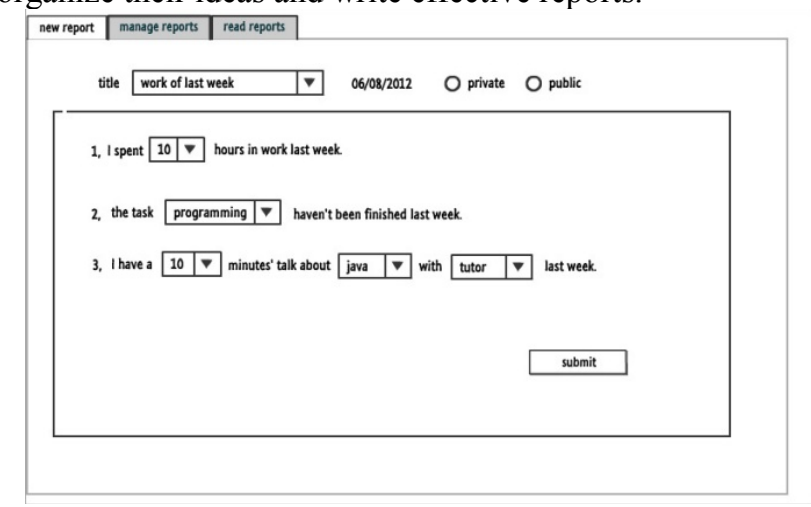

Figure 4. The learners' interface: creation of new reports.

\section{CONCLUSION AND FUTURE WORKS}

In this paper, we presented an architecture of PBLMS to supply learners with indicators in order to support the selfregulation of their learning activities. We proposed a method to combine activity traces (log files) and reporting traces (the content of self-reports) to produce high-level indicators, which can help learners to improve their self-regulation and learning strategies. The reporting traces are collected from the reporting tool we have developed. This tool provides several benefits. On the one hand, it allows obtaining data about non-instrumented activities and about the use of external tools. On the other hand, it could help learners to reflect on their activities and offer a means to share information and to communicate within the group. By using semi-structured sentences, the content of the reports is structured and organized, which allows extracting information easily and automatically. The report structures also incite learners to write information closely related to the learning activities and to organize their ideas. Finally, this tool also allows creating different report structures for different learners according to their preferences and to the context. Our next work will consist in designing the indicators and the interfaces of the dashboard in order to experiment the principle of PBLMS and the reporting tool in real courses. In a short term, we will combine the activity traces and the reporting traces to calculate indicators. In a longer term, we will study the usability and the utility of the different kinds of indicators (including their representation modes) for supporting self-regulation processes.

\section{REFERENCES}

[1] R. Mazzaand and V. Dimitrova, "CourseVis: A graphical student monitoring tool for supporting instructors in web-based distance courses", Human-Computer Studies, vol. 65, n² 2, 2007, pp. 125-139.

[2] P. Avgeriou, A. Papasalouros, S. Retalis and M.Skordalakis, "Towards a pattern language for learning management systems", Educational Technology \& Society, vol. 6, n 2, 2003, pp. 11-24.
[3] K. Cotton, " Monitoring student learning in the classroom, school improvement research series (SIRS) ", Northwest Regional Educational Laboratory, US Department of Education, 1988.

[4] C. Michel and É. Lavoué, “KM and WEB 2.0 Methods for ProjectBased Learning. MEShaT: a Monitoring and Experience Sharing Tool ", Multiple Perspectives on Problem Solving and Learning in the Digital Age, 2011, pp. 49-66.

[5] C. Michel, E. Lavoué and L.Pietrac, “ A Dashboard to Regulate Project-Based Learning ", 21st Century Learning for 21st Century Skills, Berlin, Heidelberg: Springer Berlin Heidelberg, pp. 250-263.

[6] M. Ji, “Ergonomic Study of Existing Project-Based Learning Management System ", Les quatrièmes rencontres jeunes chercheurs en EIAH (RJC EIAH 2012), 2012, pp. 57-62.

[7] Z. Jeremic, J. Jovanovic and D.Gasevic, "Semantically-Enabled Project-Based Collaborative Learning of Software Patterns ", Proceedings of the International Conference of Advanced Learning Technologies, 2009, pp. 569-571.

[8] B. Zimmerman, "Attaining self-regulation: A social cognitive perspective ", Handbook of Self-Regulation, USA, 2000, pp. 13-40.

[9] L. Gagnière, “Comment inciter les régulations métacognitives pour favoriser la résolution de problèmes mal structurés? ", $\mathrm{PhD}$ thesis, Université de Genève, Genève, 2010.

[10] C. Costa, H. Alvelos and L. Teixeira, “ The Use of Moodle e-learning Platform: A Study in a Portuguese University ", Procedia Technology, vol. 5, 2012, pp.334-343.

[11] C. Despres, "Synchronous tutoring in distance learning: A model for the synchronous pedagogical monitoring of distance learning activities", Artificial Intelligence in Education, Proceedings of the 11th International Conference on Artificial Intelligence in Education, (AIED 2003), Sydney, Australia, pp. 271-278.

[12] V. Guéraud and J. Cagnat, "Automatic Semantic Activity Monitoring of Distance Learners Guided by Pedagogical Scenarios", Proceedings of the First European Conference on Technology Enhanced Learning (EC-TEL 2006). Crete, Greece: Springer LNCS 476-481..

[13] P. Teutsch, JF. Bourdet and O. Gueye, "Perception de la situation d'apprentissage par le tuteur en ligne", Proceedings of the Conference of TICE 2004, Compiègne (France), October 2004, pp. 59-66.

[14] C. Després and T. Coffinet, "Reflet, un miroir sur la formation", Proceedings of the Conference of TICE 2004 - " Research Session ", Université de Technologie de Compiègne, October 2004, pp. 19-24.

[15] C. Laperrousaz, P. Leroux and P. Teutsch, "Analyzing a collaborative writing activity in order to improve tutor's perception of individual contributions of learners", Proceedings of the IEEE International Conference on Advanced Learning Technologies (ICALT 2005). Kaohsiung, Taiwan, pp.182-184.

[16] M. May, S. George and P. Prévôt, "TrAVis to Enhance Students' Self-monitoring in Online Learning Supported by ComputerMediated Communication Tools ", Computer Information Systems and Industrial Management Applications, vol. 3, 2011, pp. 623-634.

[17] H. S. Du and C. Wagner, " Learning with weblogs: Enhancing cognitive and social knowledge construction ", IEEE Transactions on Professional Communication, vol. 50, $\mathrm{n}^{\circ} 1$, pp. 1-16.

[18] S.K. Chu, C.K. Chan and A.F. Tiwari, "Using blogs to support learning during internship", Computers \& Education, vol.58,n`3, pp. 989-1000.

[19] P.H. Winne, A.F. Hadwin and C.L.Z. Gress, "The learning kit project: Software tools for supporting and researching regulation of collaborative learning ", Computers in Human Behavior, vol. 26, $\mathrm{n}^{\circ} 5,2010$, pp. 787-793.

[20] T. Djouad, A. Mille, C. Reffay and M. Benmohammed, "Collaborative Activity Indicators Engineering: Using modeled traces in the context of Technology Enhanced Learning Systems", research report nRR-LIRIS-2010-014, 2010, LIRIS, Université de Lyon. 